\title{
Ontognoseological limites of intuition in the structure of cognitive and creative activity
}

\author{
Arthur Bakhmetyev ${ }^{1 *}$, and Alexander Nesterov ${ }^{1}$ \\ ${ }^{1}$ Samara University, 443066, Samara, Russia
}

\begin{abstract}
The article analyzes ontological and epistemological limits of intuitive cognition in the structure of cognitive and creative activity. To conduct a philosophical analysis of the concept of intuition, dialectic, descriptive and comparative methods are used. This analysis is necessary to identify ontological and epistemological aspects of intuitive cognition. The study of ontognoseological limits of intuitive knowledge is of particular interest for understanding the specifics of the invention problem, as well as the essence of the thinking process as such. Intuition, having ontognoseological limits, allows you to create and design inventions. Intuition is a basic attribute of the creative process. The key concepts used in the article are P.K. Engelmeyer, N. Hartmann, Ayn Rand, and I.D. Levin. The basic definition of intuition formulated by Engelmeyer points to the fundamental attribute of intuitive cognition - the creation of a new one through work with experience. Thus, intuition acts as a transitional link between feeling, reason and mind. In the concept of Engelmeyer, the structure of the creating process an invention is declared. The attributive structure of intuitive cognition, built on the basis of the Hartmann and Levin concepts (intuition of contemplation, intuition of an idea, selfconscious intuition, intuition of assumption), constructs a scheme of functioning of intuition as such. In the concepts of Hartmann and Ayn Rand, intuitive cognition appears as a rational form of grasping the existing. Hartmann, Ayn Rand, and Levin, singling out the properties of rational cognition in intuition, denote the ontognoseological boundaries of intuitive cognition. Basic parameters and attributive structure of intuitive knowledge were derived. Understanding the specifics of intuitive knowledge allows creating a holistic view of the process of thinking in general.
\end{abstract}

\section{Introduction}

The problem of knowledge is the subject of epistemology, which is a fundamental discipline in the system of philosophical knowledge. Knowledge has an "activity character and the ability to generate new knowledge" [1]. The process of cognition in the field of philosophy can be understood as an internal action "with a specific purpose and carried out in appropriate conditions" [2]. In the process of cognition, a person needs to make decisions

\footnotetext{
* Corresponding author: arthurbakhmetiev1993@gmail.com
} 
"regardless of space (historical place of residence) and time (era)" [3]. Cognition comes down to building various ideas that have practical expression and "is determined by the presence of an internal perspective on the world" [4]. Ideas are the results of the process of cognition, which includes the process of cognition into its epistemological "arsenal". Cognition, according to German philosopher N. Hartmann, "is the transformation of being into an object, its objection - into a subject" [5]. The problematic nature of the universe forms different levels of cognitive activity. In the field of philosophy, two levels of cognition are classically distinguished: intuitive and rational (as indicated by N. Hartmann and B. Croce): "Philosophy has always contained some intuition" [6].

The concept of intuition to date has not found a universally valid definition and is a conglomerate of various kinds of ideas in the problem plane of philosophical knowledge. Philosophy "is a kind of scientific field of spiritual activity, it is a sphere of cognitive, not emotional thinking" [7]. Intuitive knowledge contributes to the development of scientific creativity and research. Intuition is a point inducing the development of the cognitive process in general. As the domestic thinker I.D. Levin, "intuition is a huge charge of knowledge, concentrated at one point" [8]. This article defends the thesis that intuition as a rational form of grasping the existing has ontognoseological boundaries necessary for the implementation of the cognition process. Based on the concepts of N. Hartmann, Ayn Rand, P.K. Engelmeyer and I.D. Levin fixed the parameters of the ontognoseological boundaries of intuitive knowledge.

\section{Research Objectives}

The purpose of this work is to study the ontological and epistemological aspects of intuitive knowledge in the structure of scientific knowledge, which confirm its heuristic status in the field of philosophy, as well as to construct a table of attributive characteristics of intuitive knowledge.

The objectives of this work reveal the stated purpose and include:

1. the development of a holistic concept and structure of intuitive knowledge;

2. refinement and concretization of the content of the intuition concept in the history of philosophy and scientific knowledge in general;

3. identification and analysis of ontological and epistemological limits of intuitive knowledge;

4. the construction and analysis of the attributive characteristics table of intuition in the structure of the thinking process;

5. analysis and interpretation of the intuition problem in the process of creativity.

\section{Research methods}

The method of researching intuition in its systemically important quality for the process of cognition consists in deriving the basic parameters necessary and sufficient for designing the ontogeneological boundaries of intuition. The general scientific dialectic method, which induces the principles of objectivity, historicism and systematized character, makes up the methodological basis of the study. The dialectical method is used to understand the patterns and specifics of intuitive cognition. The tasks posed in this study are solved through the integrated use of descriptive and comparative methods. The descriptive method is used for a holistic understanding of the concepts of thinkers dealing with the problem of intuitive cognition. The comparative method is used to analyze intuitive knowledge by correlating one philosophical concept with another. These methods allow us to understand the nature of intuition, to highlight the basic parameters and structure of intuitive knowledge. 


\section{Ontological boundaries of intuitive knowledge}

The problem of cognition is reflected in the philosophy of the German thinker and author of critical ontology N. Hartmann. He assigns the problem of cognition to the role not of a logical or psychological problem, but of a metaphysical one, because the essence of cognition is that "the being is made the subject of the subject" (Gartman N., 2003). As for the nature of the process of cognition, Hartmann writes the following: "The process of cognition has no effect on the existing as the being; it remains itself "[5]. Hartmann associates cognition with grasp. "Cognition is not the same as thinking or visual representation; it is not the production of contents, not even just the "possession" of contents, but in essence - "grasping" in-itself-being" [5]. An ontologically grounded intuition appears as a form of "grasping" or cognition of an object, allowing connecting ideal and real being. From Hartmann's point of view, "perceiving does not mean having-inconsciousness". The relation of the subject to his in-itself-existing object is completely onesided here: it is receptive. A being that becomes an object, i.e. something perceived, does not experience any impact; nothing changes in it. Only in the subject changes occur: he receives knowledge about the subject" [5].

Intuition "with full right is a form of grasping (cognition)" [5]. Intuition is a "mode of knowledge, i.e. a kind of "grasping", a transcendental act" [5]. He identifies two intuitive factors: stigma and transparency. Stigmatism is a semblance of a posteriori knowledge: it is in the lower plane of the observed. This kind of intuition does not need any symbols. This kind of intuition is the contemplation of the whole, complex and basis. Stigmatism least grabs the connections and relationships between complexes of objects. Perspectivity is seen on a larger scale. Hartmann believes that it is "an a priori understanding (Begreifen) of ideal relationships and dependencies, relationships and patterns of both conditioned and conditioning in ideal being" [5]. This feature of intuition includes pure (logical) thinking, but it does not come down to it.

\section{The epistemological boundaries of intuitive knowledge}

The epistemological concept of the American philosopher Ayn Rand has an objectivist character. Cognition "is a process of understanding, it is not a passive, but an active state, consisting of two significant parts: differentiation and integration" [9]. These cognitive processes are aimed at the emergence of concepts. Ain Rand objectivism is manifested in the fact that objectively there is one reality, expressed in concepts. For her, the objectively existing reality is the Absolute, expressed in the concept. Concepts are "products of a special kind of relationship between them (subject and object)" [9].

Intuition in the objectivist philosophy of Ayn Rand is a transition between sensation, perception, and intelligence. Intuition, working with experience, directly relies on the starting points, namely on axioms.

The epistemological aspects of intuitive cognition were discussed by I.D. Levin. According to his theory, intuition, being predicative knowledge, provides both the content of mathematics and logic, and their formalization. Intuitive knowledge as a system-forming stage of cognition includes and combines two necessary attributes of real knowledge: content and reliability, intuition is "a huge charge of knowledge, concentrated at one point" [8]. At this point, all the fullness of knowledge, all its absoluteness, is concentrated.

In Levin's concept, a distinction arises between intuition and intuitiveness. In intuitiveness, we cannot fully and accurately represent the object of our ideation. For example, we cannot accurately represent a large number so that subsequently it does not need experimental verification. Through intuition, we can magnetize an object and magnetize in its entirety. 


\section{Intuition in the process of creativity}

The creative process is an exceptional property of human nature. The idea within the ontological and epistemological boundaries should be implemented in practice. It should be based on the identification of creativity and life, which was formulated by P.K. Engelmeyer. He writes: "human creativity is only a continuation of the creativity of nature. Both this and the other make up one row, never interrupted anywhere, for creativity is life, and life is creativity" [10]. Technique and labor in the creative process are necessary, as the Russian thinker I.I. Lapshin: "Creativity is a bizarre combination of hard work and free, relaxed play" [7].

An invention is a "trinomial" [10], consisting of a principle, a scheme, and a construction. The principle gives the essence of the invention. Engelmeyer writes: "The principle gives what, although not enough, is necessary to achieve this effect" [10]. The scheme reveals the "complete ideological content" [10] of the invention sui generis, "the complete thought of it" [10]. Finally, the design provides the formal scope of the invention. "A scientific discovery or invention is always made at a certain point in time, which means that it can be surpassed. And in this sense, any scientific achievement loses relevance" [11].

Engelmeyer points to the relationship of the "trinomial" and the "three-act". The first is what any invention consists of, and the second is how it is created. A trinomial is structure and result, a three-act is a process. In his concept, Engelmeyer introduces the stages of development of any invention. These stages are induced in the concept of "three act". Engelmeyer writes: "Three figures of creativity, that is, desire, knowledge and skill, which we share only for the purpose of study, make up the trinity of creativity inseparably and indescribably, and the three act-functions of these figures make up one three-act" [10]. Figures of creativity are desire, knowledge and skill.

1. The first act is an act of intuition and desire. At this stage, the origin of the design is important. "Design, as well as inventions, suggests that the conditions have already been created" [10]. The result is an idea, that is, an idea for a future invention.

2. The second act is the act of knowledge and reasoning. Here is the development of a plan or scheme. The inventor knows clearly and distinctly what he wants to create. It is important for him that he can create. P.C. Engelmeyer writes: "the mechanism of the second act consists in the production of experiments, both in thought and in practice" [10].

3. The third act is an act of skill, constructive implementation of the invention. In the third act, it is important "to constructively implement the scheme or plan and thereby implement the plan, giving a solution to the original problem" [10]. Facts, not thoughts, join the plan. Success in creating an invention depends on skill, dexterity, and routine.

\section{Attributive structure of intuitive knowledge}

From the epistemological point of view, the basis of knowledge contains indications of the inherent factors of actual knowledge. "The act of cognition assumes that what is known exists in itself and is not affected by knowledge, does not change under its influence" [12]. It is the foundations on which the judgment is based that fall into four types of truth, in each of which the truth appears in a different quality: 1) metalogical truth;2) logical truth; 3) empirical truth; 4) transcendental truth. They exhaust the actually known in the composition of experience. These are essentially limits in which intuition exists and works.

1. In metalogical truth, the basis is the formal conditions of thought embedded in the mind, cognizable by the self-investigation of the mind. Therefore, in this type of truth, "Intuition of contemplation" is realized, which is formed through intuitiveness (according to Levin) and stigmatic intuition (according to Hartmann). "Intuition of contemplation" cognizes things through an inner feeling. 
2. Logical truth is the truth of judgment, which is due to its formal logical structure. In logical truth, the basis is another proposition in which truth acts as formal or logical. Here the prevalence of "logical-methodological procedures" is observed [13]. Thus, not only through comparison, but also through the summation and combination of concepts, an inference arises. Therefore, there is an "intuition of an idea", which is formed through intuitiveness and abstract intuition, that is, it turns out that we represent a holistic object, but in relation to other objects.

3. The empirical type of truth is a type of truth in which the basis is a judgment mediated by feelings and based on experience, so, it is the direct connection between reason and mind is expressed. Therefore, "self-conscious intuition" is realized here, in which the material object is cognized through itself. This suggests that "self-conscious intuition" is formed through intuitiveness and stigmatic intuition, since a particular object can be magnetized without touching its connections with other objects, that is, to focus its attention exclusively on this object.

4. In transcendental truth, the basis is a synthetic judgment a priori, based not only on experience, but also on the conditions of empirical possibilities that are inherent in us. Therefore, in this type of truth, the "intuition of the assumption" is realized, which is formed through intuitiveness and abstract intuition, since the object, which is determined through the relationship with other objects, cannot be magnetized by us.

\section{Findings}

From what has been said, it becomes obvious that intuition is a rational form of grasping the existing (real and perspective). Or in the words of Levin: "Intuition is a judgment on the idealized (universal) ideal subjects stricto sensu (in the narrow sense)" [8]. It is no coincidence that B. Croce notes: "intuitions of the real and ideal in reality will not be intuitions of either real or surreal, but pure intuitions. Where everything is real, there is nothing real ... Intuition is an inseparable unity of perception of the real and simple image of the only possible" [14]. In intuition, time and space merge together. Identifying the specifics of space and time is the task of subsequent reflection. Intuition filters various empirical data obtained through perception, and builds a holistic object based on experimental data. It is no coincidence that Hartmann writes: "Cognition is only about the fact that for a start there is regardless of whether it is known or not" [5]. Thus, intuition carries out work with experimental data, translating them into research, in the understanding of Hartmann, or into the conceptual stage, according to Ayn Rand.

Thus, intuition is "that remnant of rational, incontrovertible and indisputable knowledge that persists if one rejects the excessive claims of Plato, Descartes, Spinoza, Leibniz, Husserl. This is what forms the basis of all knowledge, makes any assumption possible .... It represents, in a sense, point knowledge, i.e. the point at which absolute knowledge is concentrated, but devoid of extension" [8].

In ontology, the boundary is at the level of stigma and transparency. In epistemology there is the opposition of the intuition and intuitiveness. The epistemological boundary is associated with the inability in direct intuition to see the need for too complex ideal formations.

\section{References}

1. A.O. Karpov, The basic theoretical concepts of a knowledge society,/ Bulletin of the Russian academy of sciences, 85(9), 812-820 (2015). 
2. I.A. Vasiliev, The problem of reflection and generation of meanings in human thinking, Siberian Psychological Journal, 67, 27-43 (2018).

3. V.S. Diev, G.V. Sorina, I.N. Griftsova, Ancient intellectual practice as the forerunner of the modern theory of decision making, $\Sigma \mathrm{XO} \Lambda \mathrm{H}, \mathbf{1 1 . 2}$, (2017).

4. M.D. Miroshnichenko, Phenomenologization or naturalization? Between Philosophy and Cognitive Science, Epistemology and Philosophy of Science, 56(1), 65-80 (2019).

5. N. Hartman, Towards the founding of ontology (Nauka, Moscow, 2003).

6. A.A. Krotov, Marsial Gerou and Henri Bergson: the collapse of the intuitive model?, Bulletin of St. Petersburg University. Philosophy and conflictology, 34(4), 523-533 (2018).

7. I.I. Lapshin, The philosophy of invention and invention in philosophy. Introduction to the history of philosophy (Republic, Moscow, 1999).

8. I.D. Levin, Compositions, Volume I (Radix, Moscow, 1994).

9. A. Rand, Introduction to Objectivist Epistemology (Astrel, Moscow, 2012).

10. P.K. Engelmeyer, Theory of creativity (Book House LIBROCOM, Moscow, 2010).

11. A.Yu. Antonovsky, Scientific knowledge as a concept of social philosophy, Questions of philosophy, 12, 86-89 (2018).

12. M. Gusev, The question about the "existing as the present" $n$. hartman and the question about the "meaning of being" $m$. heidegger: two look at ontology, HORIZON. Phenomenological studies, 8(1), 67-86 (2019).

13. A.V. Korzhuyev, N.N. Antonova, Logical and epistemological format of pedagogical knowledge and evidence-based pedagogy, Higher Education in Russia, 27(10), 136145 (2018).

14. B. Croce, Anthology of works on philosophy (Pneuma, St. Petersburg, 1999). 